\title{
Establishing the Quantitative Thinking Program at Macalester
}

David Bressoud

Macalester College, bressoud@macalester.edu

Follow this and additional works at: https://digitalcommons.usf.edu/numeracy

Part of the Mathematics Commons, and the Science and Mathematics Education Commons

\section{Recommended Citation}

Bressoud, David. "Establishing the Quantitative Thinking Program at Macalester." Numeracy 2, Iss. 1 (2009): Article 3. DOI: http://dx.doi.org/10.5038/1936-4660.2.1.3 


\title{
Establishing the Quantitative Thinking Program at Macalester
}

\author{
Abstract \\ In November 2005, the faculty of Macalester College voted to institute a graduation requirement in \\ Quantitative Thinking (QT) that is truly interdisciplinary. It currently draws on courses from thirteen \\ departments including Anthropology, Economics, Geography, Political Science, Theater, Mathematics, \\ Environmental Science, and Geology. This article describes the process that led to the creation of this \\ program. It explains how we were able to get broad buy-in at the beginning and the long process of trial \\ and error-informed by formative assessment-that was needed to refine the initial vision and shape it \\ into a viable program that would be accepted by most of our faculty. The article concludes with a \\ description of the program as it now exists, a discussion of our ongoing assessment of the program and \\ its effectiveness, and a discussion of the lessons we learned in the process.

\section{Keywords} \\ quantitative thinking, graduation requirement \\ Creative Commons License \\ (c) (1) (9)
}

This work is licensed under a Creative Commons Attribution-Noncommercial 4.0 License 


\section{Background and Origins of the Program}

Macalester College is a highly selective liberal arts college of 1900 students located within the city of Saint Paul, Minnesota, the state's capital. Hubert Humphrey once taught here. Walter Mondale and Kofi Annan are alumni. The college has a reputation for being strong in the social sciences and very politically engaged. A commitment to internationalism has been a hallmark since the 1940s when Macalester became one of the first colleges to fly the United Nations flag.

In the summer of 2001, under a grant from the William and Flora Hewlett Foundation, the college organized faculty discussion groups to begin taking a critical look at the curriculum, in particular at the graduation requirements, with an eye to how it might be improved. Macalester's graduation requirements consisted of distribution requirements that included any two courses from the Science Division (including Mathematics and Computer Science), plus requirements in foreign language, international diversity, and domestic diversity. While many Macalester students did study mathematics or statistics, about a quarter of the student body avoided any courses with meaningful quantitative content.

That spring, a survey of our alumni had revealed that we were significantly below peer institutions in the proportion of our graduates using quantitative tools in their current activities. There was a growing awareness that our faculty culture was one that tolerated an aversion to quantitative thinking. This was becoming particularly acute in the social sciences where many departments found themselves split between older faculty who were uncomfortable with quantitative methods and younger faculty who embraced them.

I agreed to lead a faculty discussion group on quantitative reasoning. We had high interest. The group met every other week in the fall and continued meeting every three or four weeks in the spring. Twenty-one faculty and staff participated in some way during this year, and we had a core group of a dozen who showed up regularly. Three people played particularly important roles: David Lanegran, the chair of the Geography Department who, as both a Macalester alumnus and one of our longest serving faculty members, is highly respected on campus; Vasant Sukhatme, chair of the Economics Department, who was instrumental in bringing that department firmly behind the initiative we would develop; and Danny Kaplan, an applied mathematician in the Department of Mathematics and Computer Science who brought energy, enthusiasm, and a total dedication to this project. The other departments represented in the planning process were Biology, Physics, Political Science, Psychology, and Sociology. In addition, the Dean of Academic Programs was a regular participant.

It did not take us long to agree on what we meant by quantitative reasoning.

It included an understanding of sampling methodology and polling, experimental 
design and hypothesis formation, basic descriptive data, and correlation. A summary that we often invoked was that we wanted all of our students to be able to read quantitative information in The New York Times with critical understanding.

While it was easy to agree on the goal, it was much harder to find a way to get there. We struggled for several meetings to find a core of topics that could be incorporated into the introductory courses in a wide variety of departments, with the intention that all students would be required to take one of these introductory courses. But no one was willing to turn over the time needed to cover the quantitative topics that were not already part of their syllabus.

By early November, we had found a solution. Students in all of the participating introductory courses would be required to attend a common evening session that would cover quantitative topics that they might not see in their home course. In line with the interest of our students, this evening session would focus on quantitative reasoning for the purpose of analyzing questions of public policy. It would be a common experience in which students in many different classes, studying an issue of public importance from many different perspectives, could come together to hear experts in the field, share their insights, and gain an appreciation for a basic core of approaches to understanding quantitative information. We named our program Quantitative Methods for Public Policy (QM4PP).

We decided that each year would have a different public policy theme. We chose the school voucher debate for the first year because it is a well-focused issue for which there is a rich collection of data, and also because it was a pet interest of the Dean of the Humphrey Institute of Public Affairs at the University of Minnesota, an organization that we wanted to involve.

We had strong support from President McPherson who promised sufficient funds to get the program started. I spent the spring of 2002 writing grant proposals and organizing a planning workshop that drew fourteen members of our own faculty as well as interested participants from Carleton, Grinnell, Lawrence, and St. Olaf. That summer, we were awarded funding by both FIPSE and the NSF. In the fall, we launched with five participating courses, two from Mathematics (discrete mathematics and statistics) and one each from Economics, Geography, and Political Science.

\section{Trials and Tribulations}

We ran into problems almost immediately. Broad participation was difficult to get because most faculty did not want to risk losing students from their introductory courses by requiring that they also sign up for the QM4PP class. We tried 
allowing faculty to make participation by their students voluntary. To no one's surprise, students did not enroll in QM4PP unless they were required to do so.

We had trouble figuring out exactly how the common evening class would connect to the individual participating classes. The original plan was to grant each instructor the freedom to decide how to establish these ties. Without guidance or mechanisms for enabling the connections, they often did not happen. The class time of Wednesday evening meant it was difficult for participating faculty to attend, aggravating the disconnect between what happened on Wednesday evenings and what was happening in the participating classes.

The topic of school vouchers was not ideal. We learned that most college students do not understand or at this point in their lives truly care about issues of public education.

But the biggest problem was at the core of what we were trying to accomplish: a common experience that these students could share. This necessitated about 120 students coming together for a single large class on a weekly basis. We had little experience with teaching large classes, and the students, most of whom had chosen Macalester because of its small classes, were resistant.

Formative assessment was always an important part of our process, ${ }^{1}$ and before the first semester was completed we were making adjustments. One of these was to select immigration as the policy topic for the following year. This resonated with many faculty across the social sciences and humanities, could be tied to issues that energized our students, and was rich in possibilities for quantitative exploration. We held an initial planning workshop in January of 2003 involving sixteen Macalester faculty and a variety of community leaders working with immigrant issues in the Twin Cities. The January planning workshop was followed by a more extensive workshop in May of 2003.

Other adjustments were put in place. We began to explore ways of improving our teaching within a large class setting. This included the adoption of clickers and breaks for small group interaction during each class. The second and third years went much better, but the problem of getting faculty to require their students to participate in the program continued to plague us.

Fortunately, both the Economics and Mathematics departments were solidly behind this initiative. Most of the courses in Principles of Economics or Introductory Statistics participated. We had a sufficient number of students enrolled to run a meaningful program. We had envisioned our program as one that would reach math-averse students. Economics and statistics were not the courses

\footnotetext{
${ }^{1}$ Jack Bookman was our consultant on assessment. Working with Dave Ehren, math specialist in the Macalester Excellence Center, he enabled us to keep abreast of what was and was not working in the class and helped us to consider alternatives.
} 
we had originally targeted, but we did have something to offer even these students. They would see how what they had studied in class played out in thinking about public policy debate. Still, it was clear we had a long way to go if we were to turn this into a program that would reach the students we felt most needed what we were offering. We hoped that once we had fixed the initial problems and QM4PP had become a graduation requirement, we would get broader participation from other departments.

\section{Toward a Graduation Requirement}

During the academic year 2003-04, the faculty committee on Educational Policy and Governance (EPAG) began to work on revisions to the graduation requirements. With the committee leadership shared by an economist and a political scientist, we were hopeful that they would recommend that the QM4PP program be adopted as a graduation requirement, thus giving many more departments an incentive to require their students to participate. But the work of the committee dragged into a second year when the leadership was transferred to a member of the Art Department, and the committee became skeptical of any requirement for quantitative thinking.

Facing an unsympathetic EPAG committee and with our funding approaching its end, the future of a Quantitative Thinking (QT) requirement looked dark. Fortunately, over the years we had involved many of the Macalester faculty in a variety of aspects of the program: as guest speakers, as workshop participants, by bringing to campus some of the people they were interested in hearing. A total of 43 faculty, one in four of all our faculty members, representing sixteen different departments had participated in some way since the faculty discussion group began in Fall, 2001. QM4PP had built a broad base of general good will on campus. Our new president, Brian Rosenberg, made it clear that, while this was a faculty decision, he supported our efforts. By the end of the 2004-05 academic year, EPAG acknowledged the support we had on campus by agreeing to consider a proposal for a QT requirement. They gave us until September to specify exactly what it would entail.

As we strategized what we should put before the faculty, we realized that the common evening class would not fly. We had not been able to find an effective mechanism for integrating this common class into what was happening in each of the various participating classes. More importantly, we had been giving pre- and post-tests to assess how much the students were actually learning in our course. While we saw some improvement in some tasks and understandings, we were not seeing a dramatic improvement in either attitude or ability. One evening a week for a little more than an hour did not give us the opportunity for either the breadth or depth that would be needed in order to have a real impact on quantitative 
reasoning. Moreover, we were still encountering student resistance to the large class format.

Danny Kaplan led the efforts that summer to hammer out an agreement that would be built on individual courses and involve more departments. There were two directions we could have gone. One was to identify courses with significant quantitative content in the context of social issues, courses such as Principles of Economics, Introductory Statistics as taught at Macalester, or a methods course in Psychology, Sociology, or Political Science, and to require all students either to take one of these or to take a general course that would build on the case studies and other materials developed in QM4PP. The other possible direction was to encourage many courses to include a quantitative module or component, and to require students to take several of these courses. The former option had the advantage that students would get an in-depth experience in using quantitative reasoning. The advantage of the latter was the sustained and varied exposure to quantitative reasoning.

The agreement reached that summer was to embrace both options.

\section{The Final Solution}

What emerged from the summer deliberations is somewhat complex, but the faculty accepted it - almost unanimously_and it works. At its heart is a refined definition of what we mean by quantitative thinking:

1. Describing the World Quantitatively: Much of quantitative thinking involves quantitative or statistical descriptions of social and natural phenomena. This includes descriptions of patterns and variations and rates of change, such as linear or exponential growth. Understanding descriptive statistics and the various modes of presentation of quantitative data is central. Students should be able to distinguish when quantitative approaches are appropriate and when they are not.

2. Evaluating Sources and Quality of Data: Students of quantitative thinking should also understand the sources of data, including the processes of collecting or producing data. This may involve understanding how to assess the reliability and validity of measurements and elements of probability and sampling, including sources of bias and error.

3. Association and Causation: The quantitative thinker knows the ways that associations between factors are established by observation, experiment or quasi-experiment. It is important to be able to establish the meaning of an association or correlation and learn the protocols for weighing the statistical significance and theoretical importance of findings, including inferring causation. 
4. Trade-Offs: Most decisions, whether public or private, individual or societal, may be thought of as involving conflicting goals. Much of the debate on public issues involves disagreement about the value of the different goals. Where there are conflicting goals, quantitative thinking offers techniques for weighing the relative impact of policy options. While there rarely is a single correct outcome in the face of such conflicts, the quantitative thinkers can bring measure and balance to policy discussion.

5. Uncertainty and Risk: Few things in life are certain; decisions and debate often revolve around unknowns. The quantitative thinker possesses skills that can be used to assess, compare and balance risks, and understands the limits and strengths of these techniques. The quantitative thinker knows that, in the face of the unknown, if not the unknowable, we often rely on conditional statements and probabilities in making decisions and can evaluate conclusions drawn from conditional statements.

6. Estimation, Modeling, and Scale: The quantitative thinker understands that quantities vary over huge ranges; 'big' and 'small' are not absolute notions but depend on context or scale. Quantitative thinkers appreciate the value and limitations of abstracting out detail — constructing modelsand that the sensitivity of model results to assumptions can and should be reported along with the model results.

Courses in Quantitative Thinking (QT) are designated at one of three levels:

- Q3 The great majority of material covered in a Q3 course focuses on quantitative topics, and a Q3 course covers all or nearly all of the six learning goals.

- Q2 At least half of the material covered in a Q2 course focuses on quantitative topics, and a Q2 course covers the majority of the six learning goals.

- Q1 A Q1 course covers some of the six learning goals, and quantitative thinking elements represent some of the overall material covered in the course.

A student satisfies the QT requirement by taking either one Q3 course, two Q courses at least one of which is Q2, or any three Q1 courses. While the student who opts for three Q1 courses may not experience all six of the core goals of QT, it was decided that trying to keep track of which had not been covered would be a logistical nightmare. In view of the extended exposure to QT such students would receive, we could live with less than perfect coverage.

The designation is awarded for a particular class taught by a particular instructor during a particular semester, although when that instructor wants to teach that class again for QT credit, the vetting process is reduced to going online and checking a box that requests this designation and asserts that no substantial 
changes have been made to the course. For a first time request, the instructor fills out an online form that asks which of the six goals will be addressed, how they will be addressed, and how students will be assessed.

The fact that this is a QT requirement, not a mathematics requirement, is reflected in that many mathematics course as well as many courses in the natural sciences that are mathematically intensive receive no Q-designation, or only a Q1. The six goals were written to reflect the importance of being able to apply QT to the process of thinking about public issues. A course that does not do this, even were it to be billed as introductory statistics, would not qualify for Q3.

For Fall 2008, 48 sections of QT courses were offered, representing the departments of Anthropology, Biology, Chemistry, Economics, Environmental Science, Geography, Geology, Mathematics, Music, Physics, Political Science, Psychology, Sociology, and Theater and Dance. Thirty-two of these sections were designated Q1, four were Q2 courses, and twelve were sections of one of the following Q3 courses: Data Analysis and Statistics, Introduction to Statistical Modeling, Principles of Economics, Empirical Research Methods in Political Science, Research in Psychology, and the course that is dearest to my own heart, Quantitative Thinking for Policy Analysis. Because QT is now a graduation requirement and thus including enough quantitative material for a Q1 course makes your course more attractive to students, we have not had trouble enlisting Q1 courses. The Q2 designation is not used very much, but we never expected it to be.

\section{QM4PP becomes QT4PA}

QM4PP was always a misnomer since the focus was never on methods. The relaunch in Fall 2005 gave us the opportunity to rebrand the course as Quantitative Thinking for Policy Analysis (QT4PA). It is the direct descendant of the QM4PP course, scaled down in class size and beefed up in content. It is a course that is offered jointly by Economics and Mathematics, with each department responsible for teaching it once a year. Limited to 35 students, it draws on the many years of experience and the many presentations, examples, and case studies developed for QM4PP. Some of the pieces that go into this course include:

- An introduction to the display of data via Gapminder (2008) and the use of Excel spreadsheets to analyze and visualize the stories the data tell. Among the data bases we explore are the Bureau of Labor Statistics, the US Census Bureau, and the World Development Indicators,

- Basic work on the use of percentages, ratios, and rates, on compounding and exponential versus linear growth, and on probabilities (even 
Macalester students need this),

- An exploration of immigration issues with analysis of the quantitative information that each side marshals to support its position,

- Sampling issues, confidence intervals, and the interpretation of polling data,

- An analysis of correlation - what it means and how it can be measuredtogether with experience through examples of the problems encountered when we try to infer causality,

- Simpson's paradox, how it illustrates the dangers of aggregating data, and an analysis of the Berkeley study of sex bias in graduate admissions (Bickel et al. 1975),

- A basic introduction to cost/benefit analysis,

- A discussion of the need for trade-offs in any process of making policy decisions, with an analysis of the power and the limitations of quantitative tools, and

- Detection, especially the role of false positives, false negatives, and prevalence in assessing the usefulness of methods of detection. This is illustrated through the analysis of issues that include catching terrorists, diagnosing diseases, and keeping unsafe food away from consumers.

The course culminates in an in-depth study in which students gather and assess quantitative and other information relevant to a policy question, draw conclusions and make recommendations, and then present these both orally to the rest of the class and in a written paper.

There is no textbook, but we do use books by Best $(2001,2004)$ and Gigerenzer (2002) as starting points for class discussion.

The course is extremely popular. Part of the reason for this is that it satisfies both the QT requirement and half of the distribution requirement for courses in the Science Division. But I also think it is popular because the course is practical, interesting, and engaging. Student feedback indicates that they enjoy the course and believe that it is providing them with a way of looking at the world that enriches their understanding of its complexities.

\section{Ongoing Assessment}

QT became a graduation requirement beginning with the class of 2011. When these students matriculated in Fall, 2007, they also became the first subject to our new college-wide assessment program. This consists of instruments designed to measure student ability in writing, quantitative reasoning, international understanding, and multicultural understanding. The instruments are administered to incoming first-year students and again at the end of the sophomore and senior 
years.

As a benchmark, we are using the Collegiate Learning Assessment (CLA) (Council for Aid to Education, 2008). Against this is an instrument that Danny Kaplan has been developing specifically for Macalester. The Macalester questions on quantitative reasoning were derived from the summative tests used for the QM4PP program. The following provide an example of the kinds of questions that are asked.

Here is the tuition (per semester) at some elite colleges in 1947 and 2007;

$\begin{array}{lll}\text { School } & 1947 & 2007 \\ \text { Princeton } & \$ 520 & \$ 16,500 \\ \text { Columbia } & \$ 544 & \$ 16,832 \\ \text { Harvard } & \$ 494 & \$ 15,728 \\ \text { Williams } & \$ 524 & \$ 16,739 \\ \text { Yale } & \$ 650 & \$ 17,265\end{array}$

During the 60-year period between 1947 and 2007, how many times has the typical tuition doubled?
A. 2 times
B. 5 times
C. 10 times
D. 32 times

A simple way to approximate the annual growth rate (in percent per year) is that the doubling time (in years) divided into 72 gives the growth rate. For example, a doubling time of 24 years corresponds to a growth rate of $72 / 24=3$ percent. This is called the "Rule of 72 " and is a useful rule of thumb.

According to the Rule of 72 , what has been the typical annual growth rate in tuition over the past 60 years?
A. 3 percent per year
B. 6 percent per year
C. 12 percent per year
D. 20 percent per year

What is the typical inflation rate in the US economy?
A. 0 percent per year
B. 1 percent per year
C. 3 percent per year
D. 6 percent per year
E. 10 percent per year 
A certain town is served by two hospitals. In the larger hospital about 45 babies are born each week, and in the smaller hospital about 15 babies are born each week. As you know, about 50 percent of all babies are boys. However, the exact percentage varies from week to week. Sometimes it may be higher than 50 percent, sometimes lower. For a period of one year, each hospital recorded the weeks on which more than 60 percent of the babies born were boys. Which hospital do you think recorded more such weeks?

A. The larger hospital

B. The smaller hospital

C. About the same (there is no reason to expect that one hospital will have more such weeks than the other)

There are many difficulties with our assessment that are still to be worked out such as how to get sophomores and seniors to take these instruments seriously and how to measure international and multicultural understanding. The CLA is very quantitative, providing a reasonable assessment of student ability to analyze quantitative information and use it effectively to support an argument. At the very least, we hope to get a good picture of how our students' ability to reason with quantitative information develops over their four years.

\section{Lessons Learned}

The lessons that we learned are very similar to those cited by Steele and KiliçBahi (2008) in their description of the development of a Quantitative Literacy (QL) program at Colby-Sawyer. These include the need for broad participation, a focus within the QL program on interdisciplinarity, a faculty culture of collaboration and innovation, a supportive administration, adequate funding, and an institutional commitment to student learning. I would add one more: a willingness to be flexible.

Institutional change is a long, slow, and uncertain process. It requires participation that is both broad and deep. We never would have succeeded if we had not touched such a large fraction of our faculty as we developed this program, and we never would have succeeded if we had not had those few people who were totally committed to this vision. We needed those who showed up regularly, those who participated occasionally, and those who limited their involvement to encouragement from the sidelines.

If this had only been a project of the Math Department, or even Math and Economics jointly, we would not have succeeded. In order to get such broad participation, the program needed to be interdisciplinary. While most of the 
leadership came from Mathematics and Economics, there were faculty from Geography, Sociology, and Political Science who were heavily involved and were able to play important roles at critical junctures.

Macalester has a very active Center for Scholarship and Teaching (CST). The QM4PP program came under its aegis, thus providing a home for clerical support and a vehicle for promoting participation. The general atmosphere of concern for excellent teaching and willingness to experiment that the CST has fostered was important in setting a context in which QM4PP could flourish.

From the initial planning session attended by the Dean for Academic Programs to the final push for faculty adoption that was unambiguously supported by our president, the administration was supportive, most significantly by guaranteeing the resources that would be needed as we made each move to the next stage.

Money is important. The task was much larger than anyone envisioned, and it would not have happened without release time for Danny Kaplan and myself. Being able to hire Jack Bookman as our consultant on assessment and Steve Holland, a PhD Economist on a half-time position to teach in and to develop materials for the QM4PP program, was very important. We ran at least one and usually two workshops per year. These provided means to educate and involve many of our faculty and made it possible to reach out to the wider community, a process that provided both support and insight. Money cannot buy the commitment that provides impetus, but it can grease a process that inherently encounters a great deal of friction.

The focus on student learning meant that few faculty argued with our goal of improving student reasoning with quantitative information. Even those who would consider themselves math averse recognized the importance and usefulness of this skill. Our challenge was limited to coming up with a program that could reach our goal efficiently.

Tenacity needs to be tempered with flexibility. Looking back, we can see that we preserved all that was really good in our initial vision, even though what did emerge is quite different from where we thought we would be. The continual process of formative assessment was punctuated at one- to two-year intervals by two-day workshops when we would bring in a few outside observers, put everything on the table, then sit back and brainstorm what could or should be done differently. On the other hand, there came the time in 2004-05 when we had to articulate a coherent plan and sell it to the faculty. One of the hardest parts of the process was determining what was essential and what was peripheral.

For those who would seek to create a program in Quantitative Reasoning at their own college or university, my advice would be to first articulate your goals in a language that makes sense for your institution, keep in mind the lessons learned at Colby-Sawyer and Macalester, and remember that an effort like this is 
only do-able and worthwhile if it is something you care deeply about and enjoy.

\section{Acknowledgments}

This material is based upon work supported by the US Department of Education Fund for the Improvement of Post-Secondary Education under Grant No. P116B020918 and the National Science Foundation under Grant No. 0229967. Any opinions, findings, and conclusions or recommendations expressed in this material are those of the author(s) and do not necessarily reflect the views of the US Department of Education or the National Science Foundation

\section{References}

Best, Joel. 2001. Damned Lies and Statistics: Untangling Numbers from the Media, Politicians, and Activists. Berkeley, CA: University of California Press.

- 2004. More Damned Lies and Statistics: How Numbers Confuse Public Issues, Politicians, and Activists. Berkeley, CA: University of California Press.

Bickel, P. J., E. A. Hammel, and J. W. O'Connell. 1975. Sex Bias in Graduate Admissions: Data from Berkeley. Science, New Series, Vol. 187, No. 4175. (Feb. 7, 1975), pp. 398-404.

Council for Aid to Education, Collegiate Learning Assessment (CLA), http://www.cae.org/content/pro_collegiate.htm, last accessed Dec 31, 2008.

Gapminder, http://www.gapminder.org, last accessed Dec 31, 2008.

Gigerenzer, Gerd. 2002. Calculated Risks: How to Know When Numbers Deceive You. New York, NY: Simon \& Schuster.

Steele, Benjamin and Semra Kiliç-Bahi, Quantitative Literacy Across the Curriculum: A Case Study. Numeracy, Vol. 1, Issue 2, Article 3. http:// dx.doi.org/10.5038/1936-4660.1.2.3 